\author{
Nano Res \\ DOI (automatically inserted by the publisher) \\ Research Article
}

\title{
Koutecky-Levich analysis applied to nanoparticle modified rotating disk electrodes: Electrocatalysis or misinterpretation?
}

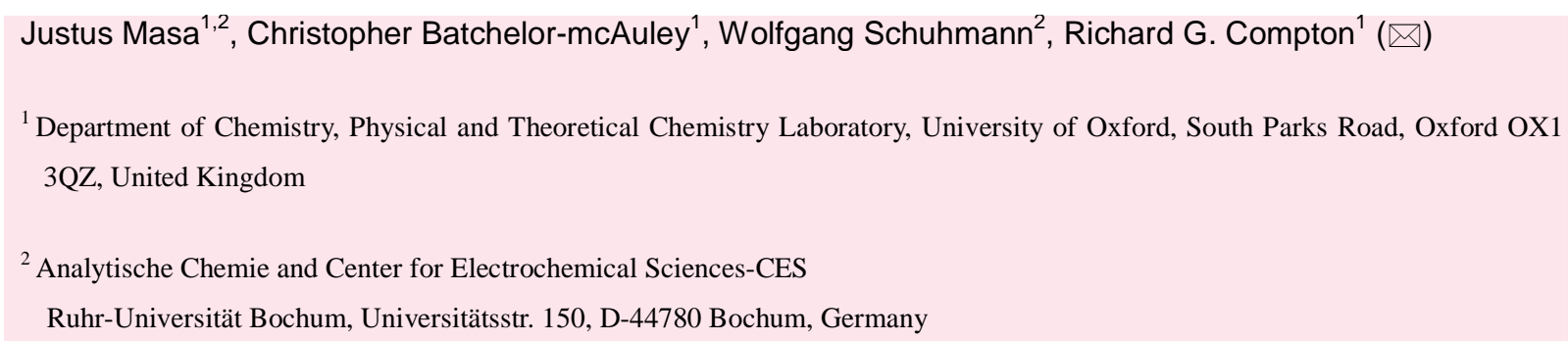

\begin{abstract}
The application of naive Koutecky-Levich analysis to micro- and nano-particle modified rotating disk electrodes of partially covered and non-planar geometry is critically analysed. Assuming strong overlap of the diffusion fields of the particles such that transport to the entire surface is time-independent and one-dimensional, the observed voltammetric response reflects an apparent electrochemical rate constant $\mathrm{k}_{\text {app }}^{\mathrm{o}}$ equal to the true rate constant $\mathrm{k}^{\circ}$ describing the redox reaction of interest on the surface of the nanoparticles and the ratio, $\psi$, of the total electroactive surface area to the geometric area of the rotating disk surface. It is demonstrated that Koutecky-Levich analysis is applicable and yields the expected plots of $\mathrm{I}^{-1}$ versus $\omega^{-1}$ where I is the current and $\omega$ is the rotation speed but that the values of the electrochemical rate constants inferred are thereof $\mathrm{k}_{\mathrm{app}}^{\mathrm{o}}$, not $\mathrm{k}^{\mathrm{o}}$. Thus for $\psi>1$ apparent electrocatalysis might be naively but wrongly inferred whereas for $\psi<1$ the deduced electrochemical rate constant will be less than $\mathrm{k}^{\circ}$. Moreover, the effect of $\psi$ on the observed rotating disk electrode voltammograms is significant, signalling the need for care in the overly simplistic application of Koutecky-Levich analysis to modified rotating electrodes, as is commonly applied for example in the analysis of possible oxygen reduction catalysts.
\end{abstract}

\section{KEYWORDS}

Rotating disk electrodes; nanoparticles; electrocatalysis, electrode kinetics, electro-reduction of oxygen,

Address correspondence to richard G. Compton, Richard.compton@chem.ox.ac.uk 
Koutecky-Levich analysis

\section{Introduction}

Encouraged by the wide spread interest in the use of nanoparticles and microparticles for the modification of electrodes so as to economically fabricate electrocatalytic surfaces for driving electrode processes, and especially oxygen reduction, we have simulated simple electrode processes occurring at stationary, partially active, non-flat electrodes [1]. Three assumptions were made: first that the electrocatalysis is confined solely to the particles (and not the substrate electrode which simply serves to electrically connect the particles), second, that the scale of surface roughness is smaller than the diffusion layer thickness and third that strong overlap between the diffusion fields of the nanoparticles occurs such that transport to the entire surface is linear ('so called case $4^{\prime}$ in the notation of Davies et al.) [2,3]. It was shown, building on the pioneering work of Amatore and colleagues [4] for the corresponding problem at flat surfaces, that the apparent rate constant of the electrode process, $\mathrm{k}_{\mathrm{app}}^{\mathrm{o}}$, is equal to the product of the true rate constant, $\mathrm{k}^{\mathrm{o}}$, and the ratio, $\psi$, where

$$
\psi=\frac{\mathrm{A}_{\text {act }}}{\mathrm{A}_{\text {geo }}}
$$

where $\mathrm{A}_{\text {act }}$ is the surface area of the electroactive particles and $\mathrm{A}_{\text {geo }}$ is the geometric area of the electrode, so that

$$
\mathrm{k}_{\mathrm{app}}^{\mathrm{o}}=\mathrm{k}^{\mathrm{o}} \psi
$$

In developing this theory, a variety of modified electrode surfaces were simulated, as shown in Fig. 1 , allowing the generalization of the results to give the following expression for the peak potential in the electrochemically irreversible limit.

$$
\mathrm{E}_{\mathrm{p}}^{\prime}=\mathrm{E}_{\mathrm{f}}^{\mathrm{o}}-\frac{\mathrm{RT}}{\alpha \mathrm{F}}\left[0.780-\ln \left(\mathrm{k}_{\mathrm{app}}^{\mathrm{o}}\right)+\ln \sqrt{\frac{\alpha \mathrm{FDv}}{\mathrm{RT}}}\right]
$$

The application of this theory to specific examples showed both generally, and for the case of oxygen reduction, that significant errors can arise in the analysis of the voltammetry of modified electrodes unless suitable care is taken [5]. The significant error is both quantitative and qualitative since for $\psi>1$ apparent catalysis can be wrongly inferred. In this paper, we extended the analysis of nanoparticle modified surfaces to cover the case of rotating disk electrodes noting that these are widely used to analyse and screen potential electrocatalysts as illustrated in table 1 for the case of oxygen reduction catalysts [9-22].
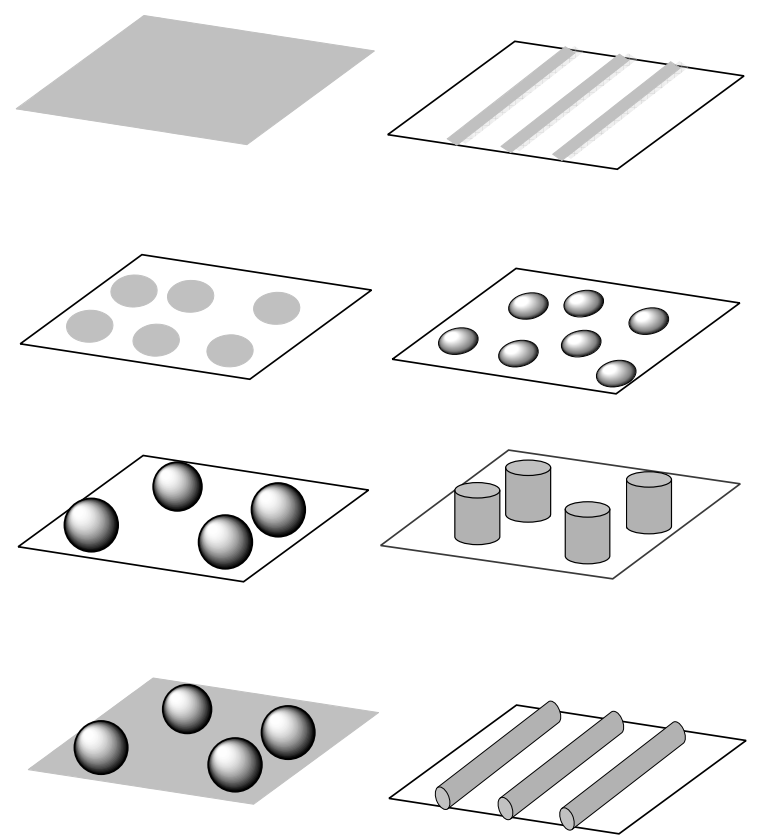

Figure 1 Schematic representation of an electrode surface modified with electrocatalytically active particles of various geometries. Shaded regions are electroactive, white regions are inactive. Adapted from [1]. 


\section{Theory}

The rotating disk electrode is a well characterized hydrodynamic electrode in which the transport, both diffusive and convective is considered one-dimensional [6].
Under steady-state conditions and considering the electrode process

$$
\mathrm{A}+\mathrm{ne}^{-} \rightarrow \mathrm{B}
$$

Table 1. Compilation of examples from literature where the activity of nanoparticle modified surfaces is compared in terms of the kinetic current $\left(\mathrm{I}_{\mathrm{k}}\right)$ on the basis of Koutecky-Levich analysis of RDE voltammetric data.

\begin{tabular}{|l|l|l|l|}
\hline Ref & Author & Year & Electrocatalysis of $\mathbf{O}_{2}$ reduction (ORR): Conclusions \\
\hline$[10]$ & Mayrhofer et al. & 2008 & Guidelines for activity measurement using RDE \\
\hline$[11]$ & Mayrhofer et al. & 2005 & ORR activity is dependent on Pt nanoparticle size \\
\hline$[12]$ & Ke et al. & 2012 & Accuracy of RDE depends on distribution of nanoparticles \\
\hline$[13]$ & Murthi et al. & 2004 & Pt-alloy catalysts - activity increase due the pre-exponential factor not activation energy \\
\hline$[14]$ & Liu et al. & 2010 & Nitrogen-doped mesoporous carbon for ORR \\
\hline$[15]$ & Erikson et al. & 2012 & ORR activity of spherical and cubic Pd nanoparticles versus bulk Pd and Pt \\
\hline$[16]$ & Inasaki et al. & 2009 & Effect of Au nanoparticles on ORR activity \\
\hline$[17]$ & Guo et al. & 2012 & PtFe nanoparticles on graphene for ORR \\
\hline$[18]$ & Liu et al. & 2012 & Bimetallic Pd-Pt nanoparticles for ORR \\
\hline$[19]$ & Zoski et al. & 2011 & Intrinsic ORR activity of Pt nanoparticles \\
\hline$[20]$ & Jirkovsky et al. & 2011 & Dependency of rate constant and ORR activity on Au nanoparticle size \\
\hline$[21]$ & Jaouen et al. & 2011 & Non-precious metal catalysts for oxygen \\
\hline$[22]$ & Si et al. & 2013 & Pt nanodendrites with enhanced ORR activity \\
\hline
\end{tabular}

sigmoidal voltammograms are expected with a steady-state limiting current Ilim

$$
\mathrm{I}_{\text {lim }}=0.62 \mathrm{nFAD}^{2 / 3} v^{-1 / 6} \omega^{1 / 2}
$$

where $\omega$ is the rotation speed $\left(\mathrm{rad} \mathrm{s}^{-1}\right), v$ is the kinematic viscosity of the electrolyte $\left(\mathrm{m}^{2} \mathrm{~s}^{-1}\right), \mathrm{D}$ is the diffusion coefficient $\left(\mathrm{m}^{2} \mathrm{~s}^{-1}\right)$ of the electroactive species of interest, $\mathrm{A}$ is the area of the electrode $\left(\mathrm{m}^{2}\right)$, $\mathrm{F}$ is the Faraday constant $\left(96485.34 \mathrm{C} \mathrm{mol}^{-1}\right)$ and $\mathrm{n}$ is the total number of electrons transferred during the electrochemical reaction.

For an electrochemically irreversible reaction, the electrochemical rate constant, k, for reaction (4) is generally given by

$$
\mathrm{k}=\mathrm{k}^{\mathrm{o}} \exp \left(-\frac{\left(\mathrm{n}^{\prime}+\alpha\right) \mathrm{FE}}{\mathrm{RT}}\right)
$$

where $\mathrm{R}$ is the universal gas constant $\left(\mathrm{J} \mathrm{K}^{-1} \mathrm{~mol}^{-1}\right), \mathrm{T}$ is the temperature $(\mathrm{K}), \alpha$ is the transfer coefficient and $\mathrm{k}^{\mathrm{o}}$ is the standard electrochemical rate constant $\left(\mathrm{m} \mathrm{s}^{-1}\right)$ and $\mathrm{n}^{\prime}$ is the number of electrons transferred before the rate determining step.

For the case of a flat uniformly accessible rotating disk electrode, Koutecky-Levich proposed a well established procedure for the analysis of 
voltammetric data at variable rotation speeds [7]. The approach is best illustrated by the early work of Vielstich and Jahn who applied the method to the study of the rates of the $\mathrm{Fe}^{2+} / \mathrm{Fe}^{3+}$ system [8]. In the following, we apply this approach and investigate numerically the effect of introducing equations (1), (2) and (6) into the analysis thus addressing the effects of sparse nanoparticle coverage and of non-flat surfaces, albeit exclusively with the case $4^{\prime}$ in the notation of Davies et al. [2,3]. This work complements and extends that summarized by Johnson et al. [9] for flat, partially blocked electrodes.

For reactions which are controlled by both diffusion and kinetics at rotating disk electrodes, the total flux, $\mathrm{j}$, of the reacting electroactive species is related to the speed of rotation of the electrode $(\omega)$ through equation (7), commonly known as the Koutecky-Levich equation.

$$
\frac{1}{\mathrm{j}}=\frac{1}{\mathrm{kc}_{\infty}}+\frac{1}{\mathrm{Dc}_{\infty} / \chi_{\mathrm{D}}}
$$

where $\mathrm{k}$ is the potential dependent rate constant of the reaction defined in equation (6), $c_{\infty}$ is the bulk concentration of the reacting species in the electrolyte and $\chi_{D}$ is the thickness of the diffusion layer given by

$$
\chi_{\mathrm{D}}=1.61 \omega^{-1 / 2} v^{1 / 6} \mathrm{D}^{1 / 3}
$$

Application of equation (7) to extract the kinetic parameters of an electrode reaction usually involves one of two common approaches. In the first case, the reciprocal of the measured current, $I$, where $I=$ $-n F A j$, at selected potentials where the reaction is controlled by both diffusion and kinetic effects (diffusion-kinetic region) is plotted against the reciprocal of the speed of rotation of the electrode, that is $I^{-1}$ versus $\omega^{-1 / 2}$. From the slope of this graph, the number of electrons (n) involved in the charge transfer reaction can be calculated, and the intercept of the graph on the $I^{-1}$ axis gives the kinetic current
$\left(I_{\mathrm{k}}\right)$. Alternatively, and more commonly, $I_{\mathrm{k}}$ is calculated from the expression

$$
\mathrm{I}_{\mathrm{k}}=\frac{\mathrm{I}_{\lim } \times \mathrm{I}}{\mathrm{I}_{\lim }-\mathrm{I}}
$$

a reformulation of (7), where Ilim is the steady-state limiting current defined in equation (5). Knowing $I_{\mathrm{k}}$, the rate constant $k$ of the reaction at a given potential is then calculated from

$$
I_{\mathrm{k}}=\mathrm{nFAk} \mathrm{c}_{\infty}
$$

$I_{k}$ is commonly normalized against the electroactive surface area of the electrode, referred to as specific activity, or against the mass of the catalyst (mass activity), or rarely and specifically for non-platinum group metal catalysts, against the volume of the catalyst (volumetric activity) [21].

\section{Results and discussion}

\subsection{Effect of variation of $k^{\circ}$ on RDE voltammetry}

The standard electrochemical rate constant $\mathrm{k}^{\circ}$ is a true measure of the intrinsic electrocatalytic activity of an electrode surface for a given reaction. Therefore, when electrode surfaces are modified with various nano- or micro-particles, experimental values of $\mathrm{k}^{\mathrm{o}}$ for a give reaction on the modified surfaces are expected to reflect differences in the intrinsic electrocatalytic activity of the particles.

We investigated the influence of the variation of $\mathrm{k}^{\mathrm{o}}$ (from $1 \times 10^{-3} \mathrm{~cm} \mathrm{~s}^{-1}$ to $1 \times 10^{-7} \mathrm{~cm} \mathrm{~s}^{-1}$ ) on RDE voltammetry by numerically solving equations 6,7 and 8 , using the following fixed parameters: $c_{\infty}=1$ $\mathrm{mM}, \alpha=0.5, v=0.01 \mathrm{~cm}^{2} \mathrm{~s}^{-1}, \mathrm{E}^{\prime}=0.0 \mathrm{~V}, \mathrm{D}=1 \times 10^{-5}$ $\mathrm{cm}^{2} \mathrm{~s}^{-1}, \omega=1000 \mathrm{rpm}$, and $\mathrm{T}=298 \mathrm{~K}$. The resulting voltammograms are shown in Fig. 2a. Evidently, whereas the potential varies with $\mathrm{k}^{\circ}$ in accordance with equation (6), the total flux $j$ to the electrode remains unaffected.

Therefore, for a given rotation speed, provided the correct laminar flow hydrodynamic conditions prevail, that is, $10 v / \mathrm{r}^{2}<\omega<2 \times 10^{5} \mathrm{v} / \mathrm{r}^{2}$, where $\mathrm{r}$ is the radius of the electrode and $v$ is the kinematic 
viscosity of the electrolyte [22], a potential shift towards a lower overpotential indicates an electrocatalytic effect.
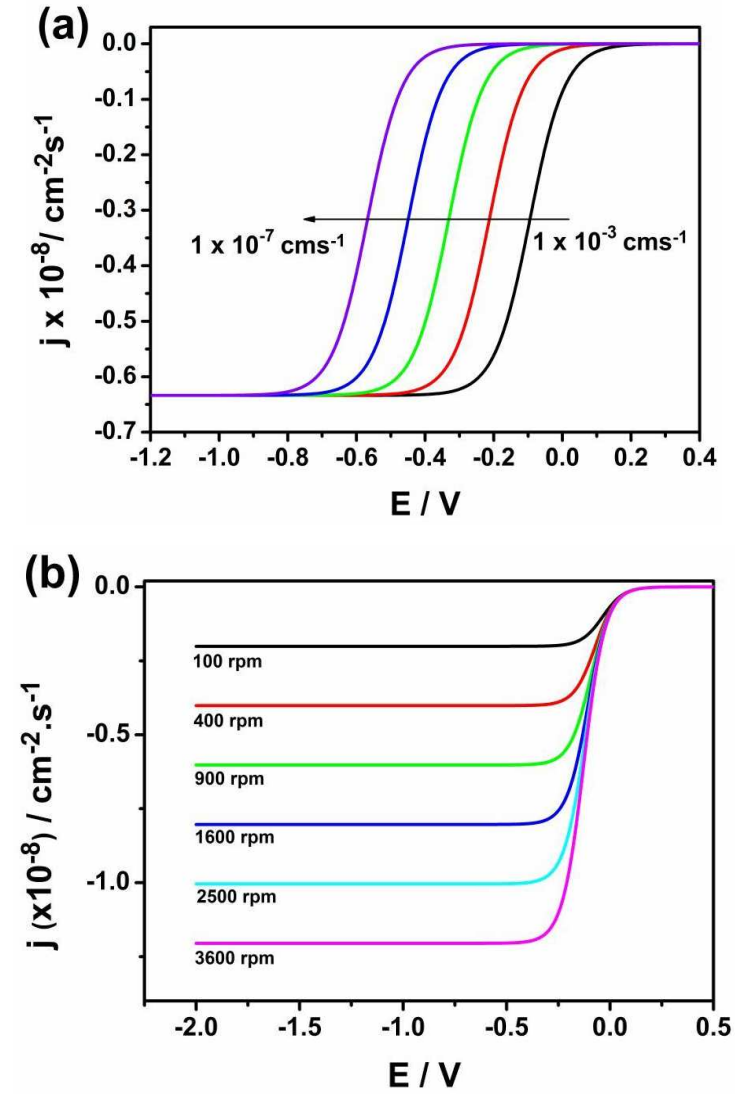

Figure 2 (a) Variation of RDE voltammetry for the reduction reaction 4 with the electrochemical rate constant $\mathrm{k}^{0} . \mathrm{C}_{\infty}=1.0$ $\mathrm{mM}, \alpha=0.50, \mathrm{D}=1 \times 10^{-5} \mathrm{~cm}^{2} \mathrm{~s}^{-1}, v=0.01 \mathrm{~cm}^{2} \mathrm{~s}^{-1}, \mathrm{E}^{\mathrm{o}^{\prime}}=0.0 \mathrm{~V}$, $\omega=1000 \mathrm{rpm}$, and $\mathrm{n}=1$. (b) RDE voltammograms at different electrode rotation speeds.

The limiting current $\lim$ (Eq. 5) is independent of the kinetics of the reaction, and the flux $\mathrm{j}$ increases with rotation speed as shown in Fig. 2b. Accordingly, a plot of the potential independent steady-state limited current Ilim against $\omega^{1 / 2}$ yields the expected linear plot through the origin (not shown), while $I^{-1}$ versus $\omega^{-1 / 2}$ at selected potentials in the kinetic-diffusion region gives parallel lines as expected, Fig. 3a. Therefore, determination of the number of electrons transferred, $\mathrm{n}$, from the slope of the $I^{-1}$ versus $\omega^{-1 / 2}$ graph is expected to yield the correct result regardless of the kinetics of the reaction, provided that the hydrodynamic conditions remain valid.
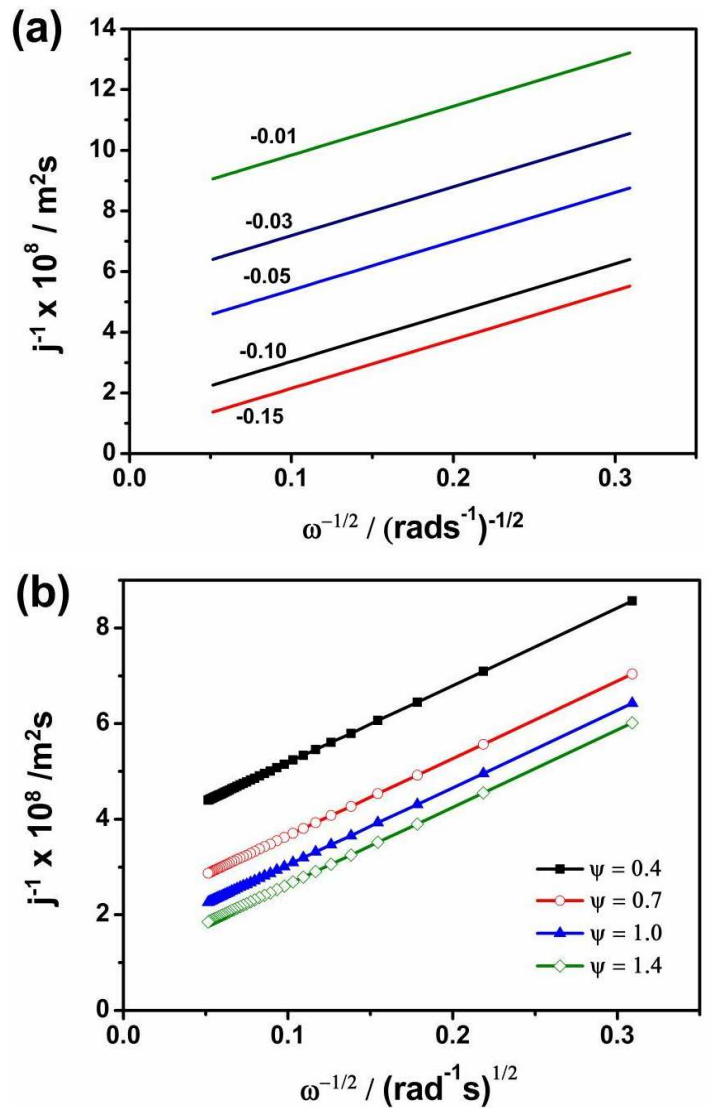

Figure 3 (a) Graph of $j^{-1}$ versus $\omega^{-1 / 2}$ at different potentials taken from the mixed kinetic-diffusion controlled region for a flat uniformly active electrode, (b) $j^{-1}$ versus $\omega^{-1 / 2}$ at $0.10 \mathrm{~V}$ for different values of $\psi$, for a partially covered, non-flat electrode.

Additionally, the kinetic currents extracted from the intercept of Fig. 3a and their corresponding values of $k$, and hence $k^{\circ}$ reflect the intrinsic electrocatalytic activity of the electrode as described by the Koutecky-Levich theory. However, distortion may arise when comparing the electrocatalytic activity of nano- or micro-particles of different materials due to involuntary variation in the coverage or the electroactive surface area of the modified surface. For example, Fig. $3 \mathrm{~b}$ shows that a plot of $I^{-1}$ versus $\omega^{-1 / 2}$ at $-0.10 \mathrm{~V}$ for different values 
of $\psi$ yields different intercepts and the consequences of this are discussed in section 3.3.

\subsection{Influence of $\psi$ on RDE voltammetry}

We investigated the influence of an electrochemically inert but electrically conductive surface which is covered with electrocatalytic nanoparticles so that the ratio of the total active surface area of the nanoparticles to the geometric area of the electrode, $\psi$, is in the range $0.2 \leq \psi \leq 1.4$, reflecting modified surfaces with the total electroactive surface area being less $(\psi<1)$ or greater $(\psi>1)$ than the geometric electrode area [1].

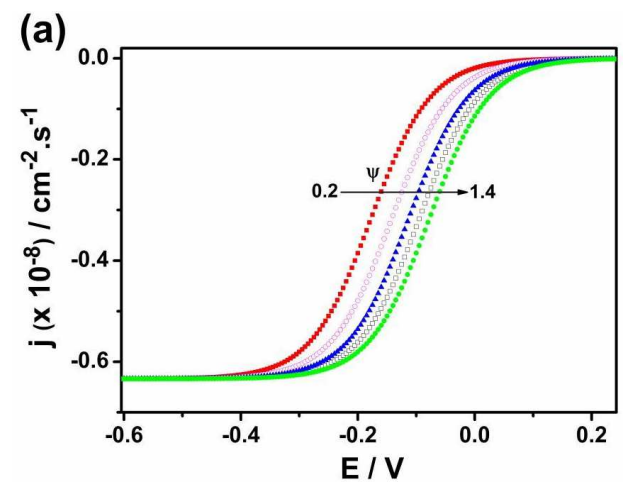

(b)

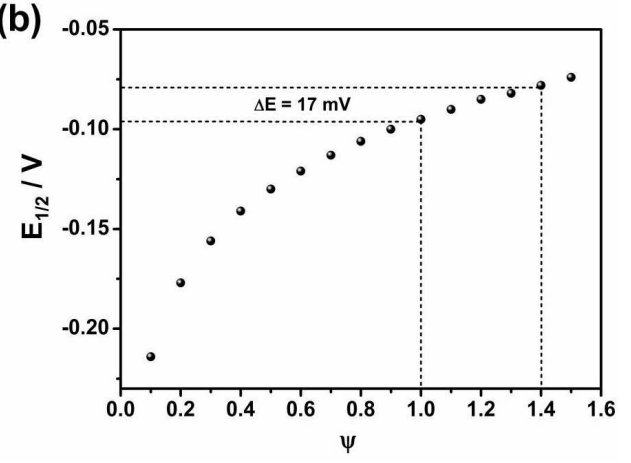

Figure 4 (a) Variation RDE voltammetry with $\psi: \square=0.2, \circ=$ $0.4, \boldsymbol{\Delta}=0.7 ; \square=1.0 ; \bullet=1.4$ (b) influence of $\psi$ on half-wave potential $\mathrm{E}_{1 / 2}$.

The dependency of the RDE voltammetry on $\psi$ was simulated using the following parameters: $\mathrm{C}_{\infty}=1$ $\mathrm{mM}, \alpha=0.5, v=0.01 \mathrm{~cm}^{2} \mathrm{~s}^{-1}, \mathrm{E}^{\prime}=0.0 \mathrm{~V}, \mathrm{D}=1 \times 10^{-5}$ $\mathrm{cm}^{2} \mathrm{~s}^{-1}, \omega=1000 \mathrm{rpm}, \mathrm{T}=298 \mathrm{~K}^{2}$ and $\mathrm{k}^{\mathrm{o}}=1 \times 10^{-3} \mathrm{~cm}$ $\left.\mathrm{s}^{-1}\right)$. The resulting RDE voltammograms for selected values of $\psi$ are shown in Fig. 4a. When $\psi<1$, the reaction proceeds at an apparently higher overpotential compared to that of a fat uniformly covered surface for which the electroactive surface area of the particles is the same as the geometric area of the rotating disc surface. On the contrary, when $\psi>1$, the reaction would appear to occur at a lower overpotential for an electrode modified with the same material.

A quantitative picture of this variation is presented in Fig. $4 \mathrm{~b}$ for the variation of the potential at half-maximum current $\mathrm{E}_{1 / 2}$ with $\psi$. In this case, without any change in the intrinsic activity, a surface with $\psi=1.4$ would appear to reduce the overpotential of the reaction by $17 \mathrm{mV}$, which might be falsely attributed to a catalytic effect.

A problem that has baffled scientists in the field of oxygen reduction for decades is the need to develop catalysts that would significantly decrease the overpotential for oxygen reduction, and indeed, despite massive financial investment and research efforts spanning decades, no major breakthrough has been reported. Consequently, even marginal reduction in the overpotential for oxygen reduction is often received with much optimism [23, 24]. However, it is clearly demonstrated here that when comparing surfaces modified with different nanoor micro-particles, a relatively lower overpotential of one modified surface compared to others may not necessarily be due a catalytic effect.

\subsection{Effect of $\psi$ on the kinetic current $I_{k}$, and standard rate constant $k^{\circ}$}

A common practice for reporting the activity of catalysts for oxygen reduction is by comparison of their kinetic currents $\left(I_{k}\right)$ at a specific potential chosen from the mixed kinetic-diffusion controlled region of RDE voltammograms, for example as reported in the literature summarized in table 1 . 
Two approaches are generally employed in obtaining $I_{k}$. In the first approach, $I_{k}$ is calculated using equation (9), or in the second, the intercept of a plot of $I^{-1}$ vs $\omega^{-1 / 2}$ is used. Knowing $I_{k}$, the rate constant of the reaction at a given potential is then calculated from equation (10). However, we see from Fig. 4(a) that at a fixed potential in the kinetic-diffusion controlled region, the calculated $I_{\mathrm{k}}$ will be different for the different values of $\psi$, and more obviously in Fig. 3(b), that different intercepts exist for the different values of $\psi$, with $I_{k}$ following the order: $1.4>1.0>0.7>0.4$.

The rate constants $k$ at variable overpotentials (E) were determined from the intercept of the plots of $I^{-1}$ versus $\omega^{-1 / 2}$, Fig. 3(b), for the different values of $\psi$ and plotted against E, Fig. 5(a).
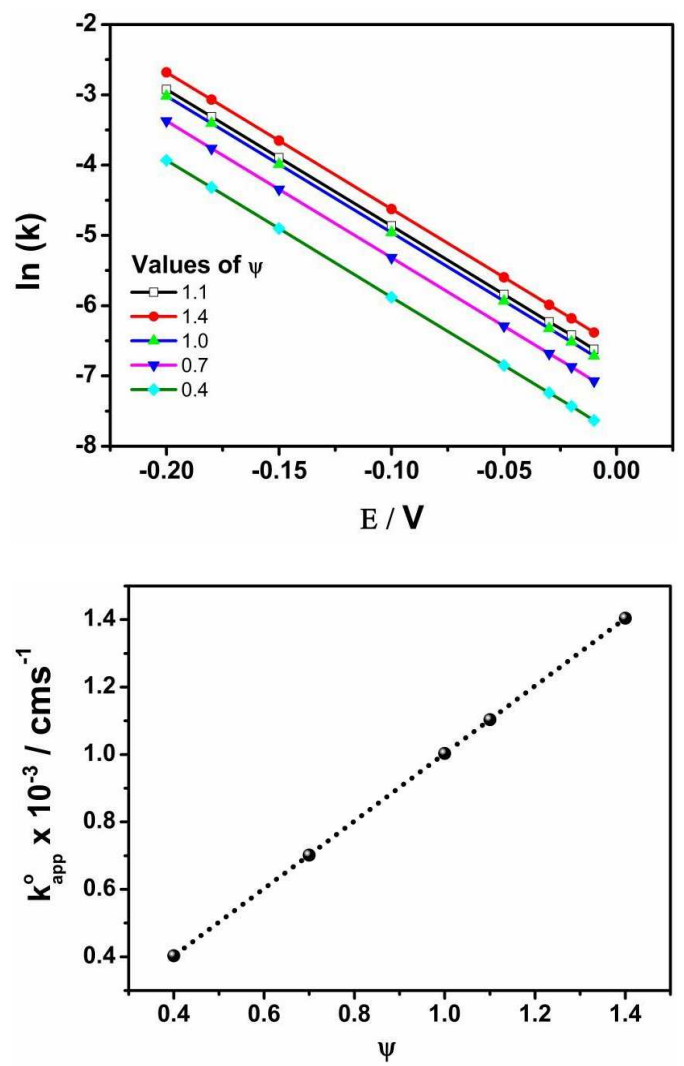

Figure 5 (a) Graph of $\ln (\mathrm{k})$ against overpotential $(\Delta \mathrm{E})$ at various values of $\psi$, (b) graph of the apparent standard rate constant $\mathrm{k}^{\mathrm{o}}$ against $\psi$.
The graphs are parallel with a slope of $-19.5 \mathrm{~V}^{-1}$ in agreement with the expected theoretical value of $\frac{-\alpha \mathrm{nF}}{\mathrm{RT}}$, taking $\alpha=0.5, \mathrm{n}=1, \mathrm{n}^{\prime}=0, \mathrm{R}=8.314 \mathrm{~J} \mathrm{~K}^{-1}$ $\mathrm{mol}^{-1}, \mathrm{~F}=96485 \mathrm{C} \mathrm{mol}^{-1}$ and $\mathrm{T}=298 \mathrm{~K}$. However, one can note that the apparent standard rate constant $\mathrm{k}_{\text {app }}^{\mathrm{o}}$ varied with $\psi$. We have called these active surface area dependent "standard rate constants" apparent rate constant $\left(\mathrm{k}_{\mathrm{app}}^{\mathrm{o}}\right)$. For $\psi<1.0$, $\mathrm{k}_{\mathrm{app}}^{\mathrm{o}}<\mathrm{k}^{\mathrm{o}}$ while for $\psi>1.0, \mathrm{k}_{\mathrm{app}}^{\mathrm{o}}>\mathrm{k}^{\mathrm{o}}$, and generally, for a given $\psi, \mathrm{k}_{\mathrm{app}}^{\mathrm{o}}=\psi \mathrm{k}^{\mathrm{o}}$, Fig. 5(b). Therefore, the rate constants of electrode catalyzed reactions extracted via the intercept of $I^{-1}$ vs $\omega^{-1 / 2}$ plots for surfaces modified with nano- and micro-particles must be interpreted taking into the discrepancy between the geometric area of the rotating disk surface and the total active surface area of the catalytic particles, if flux is known.

\section{Conclusions}

For an inert surface partially or fully covered with catalytic particles, such that the total surface area of the electroactive particles is different from the geometric area of the substrate $\psi \neq 1$, due to partial coverage of the substrate or due to extended surface area effects, the rate constants determined by the Koutecky-Levich analysis of RDE voltammetric data reflect apparent rate constants $\mathrm{k}_{\mathrm{app}}^{\mathrm{o}}$ and not true standard rate constants $\mathrm{k}^{\circ}$; and the values of $\mathrm{k}_{\text {app }}^{\mathrm{o}}$ will depend on $\psi$. For $\psi>1.0, \mathrm{k}_{\mathrm{app}}^{\mathrm{o}}$ will be greater than $\mathrm{k}^{\circ}$ and may thus be falsely interpreted to cause a catalytic effect. On the other hand, if $\psi<$ 1.0, $\mathrm{k}_{\text {app }}^{\mathrm{o}}$ will be less than $\mathrm{k}^{\circ}$, the consequence might be denial of an electrocatalytic effect even if it existed. Additionally, whereas the present results 
focused on surfaces modified with nanoparticles of various geometries, it should generally be applicable to other surfaces in which catalytic particles are used to modify a surface. Furthermore, we see that provided the hydrodynamic requirements remain valid, the diffusion limited flux is independent of $\psi$ and the determination of $n$ using the Koutecky-Levich analysis is not affected.

\section{References}

[1] Ward, K. R.; Gara, M.; Lawrence, N. L.; Hartshorne, R. S.; Richard G. Compton, R. G. J. Electroanal. Chem. 2013, 695, 1-9.

[2] Davies T. J.; Compton, R. G. J. Electroanal. Chem. 2005, 585, 63-82.

[3] Davies, T. J.; Ward-Jones, S.; Banks, C. E.; Campo, J.; Mas R.; Muñoz, F. X.; Compton, R. G. J. Electroanal. Chem. 2005, 585, 51-62.

[4] Amatore, C.; Savéant, J. M.; Tessier, D. J. Electroanal. Chem. 1983, 147, 39-51.

[5] Gara, M.; Ward, K. R.; Compton, R. G. Nanoscale. 2013, 5, 7304-7311.

[6] Pleskov, Y. V.; Filinovskii, V. Y. The Rotating Disc Electrode, Plenum Press, New York, 1976.

[7] Koutecky, J.; Levich, V. G. Zh. Fiz. Khim. 1958, 32, 1565; Doklady. Akad. Nauk SSR, 1957,117, 441; Levich, V. G. Physicochemical Hydrodynamics. Prentice-Hall, Inc., Englewood Cliffs, NJ, 1962, p 345.

[8] Jahn, D.; Vielstich, W. J. Electrochem. Soc. 1962, 107, 849-852.

[9] Treimer, S.; Tang, A.; Johnson, D. C. Electroanalysis. 2002, 14,165-171.

[10] Mayrhofer, K.J.J.; Strmcnik, D.; Blizanac, B.B.; Stamenkovic, V.; Arenz, M.; Markovic, N.M. Electrochim. Acta, 2008, 53, 3181-3188.

[11] Mayrhofer, K. J. J.; Blizanac, B. B.; Arenz, M.; Stamenkovic, V. R.; Ross, P. N.; Markovic, N. M. J. Phys. Chem. B, 2005, 109,14433-14440.
[12] Ke, K.; Hiroshima, K.; Kamitaka, Y.; Hatanaka, T.; Morimoto Y. Electrochim. Acta, 2012, 72, 120-128.

[13] Murthi, V. S.; R. Urian, R.; Mukerjee, S. J. Phys. Chem. B 108, 2004, 1011-11023.

[14] Liu R.; Wu, D.; Feng, X.; Muellen, K. Angew. Chem. Int. Ed. 2010, 122, 2619 -2623.

[15 ] Erikson, H.; Sarapuu, A.; Alexeyeva, N.; Tammeveski, K.; Solla-Gullón, J.; Feliu, J.M. Electrochim. Acta. 2012, 59, 329-335.

[16] Inasaki, T.; Kobayashi, S. Electrochim. Acta. 2009, 54, 4893-4897.

[17] Guo, S.; Sun, S. J. Am. Chem. Soc. 2012, 134 $2492-2495$

[18 ] Liu, L.; Samjeske, G.; Nagamatsu, S.; Sekizawa, O.; Nagasawa, K.; Takao, S.; Imaizumi, Y.; Yamamoto, T.; Uruga, T.; Iwasawa, Y. J. Phys. Chem. C. 2012, 116, 23453-23464.

[19] Zoski, C. G.; Fernández, J. L.; Imaduwage, K.; Gunasekara, D.; Vadari, R. J. Electroanal. Chem. 2011, 651, 80-93.

[20 ] Jirkovsky', J.S.; Halasab, M.; Schiffrina, D. J. Phys. Chem. Chem. Phys. 2010, 12, 8042-8052.

[21] Jaouen, F.; Proietti, E.; Lefèvre, M.; Chenitz, R.; Dodelet, J-P.; Wu, G.; Chung, H. T.; Johnston, C. M.; Zelenay, P. Energy Environ. Sci. 2011, 4, 114-130.

[22] Bard, A. J.; Faulkner, L. R. Electrochemical methods: Fundamentals and Applications. Wiley India Pvt. Ltd, 2004; pp 335-347.

[23] Kongkanand, A.; Kuwabata, S.; Girishkumar, G.; Kamat, P. Langmuir 2006, 22, 2392-2396.

[24] Si, W.; Li, J.; Li, H.; Li, S.; Yin, J.; Xu, H.; Guo, X.; Zhang, T.; Song, Y. Nano Res. DOI 10.1007/s12274-013-0349-z. 